\title{
GRAMSCI E O TRABALHO COMO PRINCÍPIO EDUCATIVO: ESCOLA UNITÁRIA E A CONSTRUÇÃO DA NOVA SOCIEDADE
}

\author{
Karine Martins Sobral ${ }^{1}$ \\ Ellen Cristine dos Santos Ribeiro ${ }^{2}$ \\ José Deribaldo Gomes dos Santos ${ }^{3}$ \\ Raquel Dias Araújo ${ }^{4}$
}

\section{RESUMO}

A análise crítica de Gramsci sobre a crise enfrentada pelo sistema educacional italiano no Século XX não perdeu de vista a escola de caráter humanista que predominava antes da Reforma Gentile e a escola profissional que se tornava cada vez mais difundida na sociedade moderna, apontando, como solução para essa dicotomia, o modelo da Escola Unitária alinhada ao projeto de construção de uma nova ordem social. O estudo pretende contribuir para o exame da proposta educacional gramsciana, buscando perscrutar o caminho trilhado por Gramsci na sua elaboração a partir de seu contexto histórico-social, na tentativa de verificar a tese do trabalho como princípio educativo. A pesquisa é de natureza teórico-bibliográfica, referenciada nos clássicos do marxismo e em outros autores contemporâneos que assentam suas reflexões no referencial do materialismo histórico dialético.

Palavras-chave: $\mathrm{O}$ trabalho como princípio educativo; Escola Unitária; Ditadura Revolucionária do Proletariado.

\section{GRAMSCI AND WORK AS EDUCATIONAL PRINCIPLE: UNIT SCHOOL AND CONSTRUCTION OF A NEW SOCIETY}

\begin{abstract}
Gramsci's analysis of the crisis faced by the Italian educational system in the twentieth century did not lose sight of the humanist character of the school that prevailed before the Gentile Reform and vocational school that became increasingly widespread in modern society, pointing, as a solution for this dichotomy, the Unitary School model in line with the project of building a new social order. The following study aims to contribute to the analysis of Gramsci's educational proposal, seeking peer into the path trodden by Gramsci in its development from its historical and social context in an attempt to verify the thesis work as an educational principle. The research is theoretical and bibliographical, referenced in Marxist classics and other contemporary authors who based his reflections on the referential of dialectical historical materialism.
\end{abstract}

Keywords: Work as an educational principle; Unity School; Revolutionary dictatorship of the proletariat. 
O Caderno 12 é um caderno especial escrito entre 1930 e 1932, no qual Gramsci reescreve o caderno miscelâneo (notas esparsas) $n^{\circ} 4$, acrescentando alguns trechos. Tal caderno contém 38 páginas e se subdivide em três textos. Há uma sistematização nesse caderno, uma lógica interna, ainda que a este não tenha sido dada uma redação final. Entretanto, o texto também traz continuidade e ruptura. Pode-se observar, por vezes, algumas quebras no desenvolvimento do pensamento que o autor vem perseguindo, ainda que, na maioria das vezes, seja retomado. É como se estivéssemos acompanhando Gramsci na feitura de um texto a ser apresentado posteriormente em uma versão final.

Nesse ponto, como indica Nosella (1992), entendemos que a leitura do Caderno 12 nos causa a impressão de estarmos diante de um programa político, em que ele tece caracterizações mais gerais em torno da situação em que se encontra o sistema escolar, para, mediante sua constatação, propor uma alternativa, uma solução, que é o formato da Escola Unitária, que, segundo entende Gramsci (2004, p. 40), somente seria possível sobre as bases de "[...] novas relações entre trabalho intelectual e industrial, não apenas na escola, mas em toda a vida social" .

Vale a pena ressaltar a atualidade desse documento, uma vez que vivemos hoje uma crise do sistema escolar muito mais avançada, que conta com uma desresponsabilização do Estado em níveis certamente mais agudizados, colocando, assim, em última análise, a necessidade cada vez mais urgente de ruptura com a lógica desumana do capital. A crise da escola não é só da escola. Ela vem do tecido social como um todo.

Compreendemos que uma leitura minuciosa do Caderno 12 se torna importante por três motivos: em primeiro lugar, pelo fato do pensamento de Gramsci ser tomado como referência não apenas pelos teóricos que assentam suas reflexões no campo do materialismo histórico-dialético, mas também pelos seguidores do chamado pensamento pós-modernos; em segundo, porque mesmo dentro do referencial marxista há divergentes posicionamentos em torno da tese por nós investigada; e, por último, pela atualidade de suas elaborações nesse documento. Logo, vale insistir no propósito de apreender a teorização gramsciana acerca da categoria do trabalho como princípio educativo, a fim de compreender com maior precisão o emaranhado de questões presentes na elaboração de Gramsci. A atualidade desse documento lança luz sobre a crise que assola o sistema escolar, advindo, por seu turno, da severa crise que atinge todos os complexos sociais, a exemplo do educativo. Portanto, politizar a discussão em torno do papel da educação em relação ao capital sob a mediação do Estado, potencializa a urgência da ruptura com a lógica desumana do capital em crise profunda.

A polêmica em torno da dualidade entre a escola profissional e a de cultura geral não é nova, envolvendo intelectuais, revolucionários e educadores desde o advento da Revolução Industrial, estando no centro dos debates políticos na década de 1920, na Itália, dos quais Gramsci teria sido um dos protagonistas. Vale relembrar que, já eclodia, nesse momento, uma acirrada polêmica em torno dessa reivindicação. Naquela época, o debate sobre essa questão consagrou duas propostas com terminologia específica: a "escola do trabalho", identificada como escola profissionalizante; e a "escola do saber desinteressado", identificada como uma escola humanista, porém, que não nega a necessidade da formação técnica do trabalhador. A esta última, Gramsci se filia, posteriormente, desenvolvendo-a nos termos da Escola Unitária. 


\title{
Reforma Gentile, o Trabalho como princípio educativo e Escola Unitária: atualizando o debate
}

A origem do fascismo ${ }^{5}$ coincidiu com uma grave crise social aberta na Itália, vitimada duplamente: por um lado por sua participação na primeira grande guerra; e, por outro, pelo fato da revolução socialista não ter se espalhado em nível internacional. A essa época, ainda mais, a ideologia ${ }^{6}$ dominante apregoava o patriotismo, o nacionalismo, uma espécie de ultravalorização do Estado, portanto, os estudantes aprendiam na escola a amar a sua pátria de modo a demonstrar esse amor no cumprimento das leis regidas pelo Estado.

Entre 1922 e 1923, o filósofo Giovanni Gentile - que veio a ser o primeiro Ministro da Educação do regime fascista - idealiza e executa uma ampla reforma no sistema educacional italiano que herdou seu nome. Nesse período, a escola foi utilizada como estratégia política e variável econômica, ou seja, como um dos instrumentos disseminadores do ideário fascista com a intenção de criar nos indivíduos uma nova maneira de compreender a realidade e com o objetivo nítido de manter a ordem vigente que se consolidava após a tomada do poder estatal pelo movimento em 1926. Ao mesmo tempo, a escola foi posta a serviço da formação da nova mão de obra necessária à organização do capitalismo em ascensão na Itália, típica da nova indústria.

A reforma gentílica modificou o sistema educacional desde questões de ordem administrativa e financeira às legislativas, implementando a vigência de novas leis educacionais e curriculares. Todas essas mudanças estavam amparadas por uma fundamentação filosófica, ainda que não explicitada por seus executores. Para efetivar tal reforma educacional, Gentile contava com uma equipe formada por ex-alunos e amigos, todos teóricos da educação.

De acordo com Miranda e Azevedo (2007, p. 52), a reforma gentílica consistiu num esvaziamento brutal do conteúdo e numa pesada inculcação ideológica acerca do caráter do Estado. Conforme indicam os autores,

\begin{abstract}
$\mathrm{Na}$ reforma da administração escolar, Gentile envolveu medidas modernizadoras, como a promulgação na Gazeta Oficial da obrigação de concurso público para a contratação de professores e a organização dos gastos públicos com educação. Na reforma universitária, a modificação na escolha dos reitores nas universidades foi a principal delas, além das modificações curriculares que ocorreram (privilegiando o ensino artístico, e encharcando as disciplinas tradicionais de conteúdo religioso). Em se tratando da escola elementar, a preocupação de ressaltar o regime e a nação tornou-se centro das alterações gerais (grifos nossos).
\end{abstract}

Dito isso, podemos compreender melhor a análise de Gramsci no Caderno 12, ao observar que, naquele momento histórico, ocorria uma série de transformações na política educacional e que isso se dava em função do processo de crise do modo de vida que se instaurou na Itália. Com o advento da sociedade moderna, como bem assinala Gramsci (2004, p. 32), “[...] as atividades práticas se tornaram tão complexas, e as ciências se mesclaram de tal modo à vida, que cada atividade prática tende a criar uma escola [técnica (sairia melhor profissional)] para os próprios dirigentes e especialistas". E, por isso, paralelamente ao tipo de escola tradicional, humanista, "[...] destinado a desenvolver em cada indivíduo humano a cultura geral ainda indiferenciada, o poder fundamental de pensar e de saber orientar-se na vida" (GRAMSCI, 2004, p. 33), foi sendo criado todo um sistema 
educacional com o objetivo de ensinar especificamente o conteúdo necessário ao desempenho de determinada atividade prática profissional. Em suas palavras,

$\mathrm{Na}$ escola atual, em função da crise profunda da tradição cultural e da concepção da vida e do homem, verifica-se um processo de progressiva degenerescência: as escolas de tipo profissional, isto é, preocupadas em satisfazer interesses práticos imediatos, predominam sobre a escola formativa, imediatamente desinteressada. $\mathrm{O}$ aspecto paradoxal reside em que este novo tipo de escola aparece e é louvado como democrático, quando na realidade, não só é destinado a perpetuar as diferenças sociais, como ainda a cristalizá-las em formas chinesas (GRAMSCI, 2004, p. 49, grifo nosso).

Gramsci (2004) nos chama atenção, como vimos, para o aparente caráter democrático dessa escola de tipo profissional, que, por ser ampliada em quantidade, garantindo um maior acesso dos indivíduos à educação, é mostrada pelo Estado como uma escola democrática ${ }^{7}$. O filósofo sardo já enxergava que essa escola, ao contrário de democrática, visava por meio da satisfação de interesses práticos imediatos, formar rapidamente um contingente de operários qualificados para operar nas fábricas que se espalhavam num momento em que o capitalismo se encontrava em ascensão, mediante o avanço do processo de industrialização. E mais, essa escola era destinada somente para os filhos dos trabalhadores, como veremos mais adiante.

$\mathrm{Na}$ velha escola, antes da Reforma Gentile, o princípio educativo era o ideal humanista, ou seja, o que determinava a organização do programa e das disciplinas da escola eram aqueles conteúdos necessários à transmissão do legado histórico produzido pela humanidade, para que o indivíduo pudesse se conhecer, enquanto sujeito do gênero humano e se perceber consciente de sua vida e da humanidade à qual pertencia. Esse era um "elemento essencial da vida e da cultura nacionais" (GRAMSCI, 2004, p. 46). Antes, o estudante da escola média acumulava uma série de conhecimentos, na perspectiva acima anotada, e, depois da Reforma, o aluno passou a chegar à escola média sem essa bagagem de conhecimentos, despreparado para um primeiro contato com o ensino abstrato da filosofia, desvinculado de sua vida concreta, de modo que os fundamentos humanistas pudessem não fazer sentido algum.

As línguas latina e grega eram aprendidas, mecanicamente, mas existem muita injustiça e impropriedade na acusação de mecanicidade e aridez. Lida-se com adolescentes, aos quais é preciso fazer com que adquiram certos hábitos de diligência, de exatidão, de compostura até mesmo física, de concentração psíquica em determinados assuntos, que só podem adquirir mediante uma repetição mecânica de atos disciplinados e metódicos. Um estudioso de quarenta anos seria capaz de passar dezesseis horas seguidas numa mesa de trabalho se, desde menino, não tivesse assimilado, por meio da coação mecânica, os hábitos psicofísicos apropriados? Se se quer selecionar grandes cientistas, ainda é preciso grandes cientistas, ainda é preciso partir deste ponto e deve-se pressionar toda a área escolar para conseguir fazer com que surjam os milhares ou centenas, ou mesmo apenas dezenas de estudiosos de grande valor, necessários a toda civilização (não obstante, podem-se obter grandes melhorias neste terreno com a ajuda dos subsídios científicos adequados, sem retornar aos métodos pedagógicos dos jesuítas (GRAMSCI, 2004, p. 46). 
Gramsci (2004) se refere à necessidade de disciplina para que os alunos possam adquirir o hábito do estudo que, com o avanço da ciência, poderia contar com métodos mais adequados para o alcance desse objetivo, sem retroceder aos métodos pedagógicos da escola tradicional. Nosso autor entendia ser muito difícil encontrar uma matéria que substituísse o latim e o grego, que provocasse os resultados educacionais alcançados com o ensino dessas línguas. Como nos aponta Manacorda (2008, p. 250), entendemos que a análise de Gramsci acerca do latim significa "[...] uma serena avaliação histórica da função que teve o latim, mas que não tem mais e não mais poderá ter [...]", ou seja, não se trata de retornar à escola tradicional, ao ensino do grego e do latim e sim encontrar um conteúdo que provoque o desenvolvimento intelectual provocado pelo ensino dessas línguas nas sociedades de Atenas e de Roma.

O estudo, segundo Gramsci, deve realizar-se, em sua maior parte, de forma desinteressada, ou seja, "não deve ter finalidades práticas imediatas ou muito imediatas, deve ser formativo ainda que 'instrutivo', isto é, rico de noções concretas" (GRAMSCI, 2004, p. 47). A defesa do conhecimento desinteressado, nos termos aqui referidos, expressa, com efeito, um ponto de destaque do pensamento educacional que Gramsci legou à história.

Gramsci (2004) nos esclarece acerca do impacto que a Reforma Gentile causou no sistema escolar italiano, provocando uma cisão significativamente mais profunda do que a já existente entre os diversos níveis de ensino. Antes desta reforma, a cisão se dava somente entre a universidade e as escolas profissionais. Porém, com o advento do novo sistema, passou a existir uma cisão entre a escola primária e média e a escola superior. Isto significa dizer que a fragmentação antes existente se dava somente entre os rumos acadêmicos e o ensino profissionalizante; mas que depois da Reforma passou a ocorrer entre o ensino médio e a universidade ${ }^{8}$.

A crise pela qual passava o sistema escolar, de acordo com Gramsci (2004), devia-se ao fato de que este processo de formar indivíduos especialistas em determinadas atividades práticas ocorria de forma desorganizada ${ }^{9}$, sem um plano elaborado "[...] sem princípios claros e precisos [...]" (GRAMSCI, 2004, p. 33), ou seja, negava-se o princípio humanista e abria-se uma crise pela falta de um princípio que norteasse o programa e a organização da escola. Portanto, essa crise na educação era "[...] em grande parte um aspecto e uma complexificação da crise orgânica mais ampla e geral [...]" (GRAMSCI, 2004, p. 33). Em suas palavras,

A divisão fundamental da escola em clássica e profissional era um esquema racional: a escola profissional destinava-se às classes instrumentais, enquanto a clássica destinava-se às dominantes e aos intelectuais. O desenvolvimento da base industrial, tanto na cidade como no campo, gerava a crescente do novo tipo de intelectual urbano: desenvolveu-se, ao lado da escola clássica, a escola técnica (profissional mas não manual), o que põe em discussão o próprio princípio da orientação concreta de cultura geral, da orientação humanista de cultura geral fundada na tradição greco-romana. Esta orientação, uma vez posta em discussão, foi afastada, pode-se dizer, já que sua capacidade formativa era em grande parte baseada no prestígio geral e tradicionalmente indiscutido de uma determinada forma de civilização (grifos nossos).

Naquele momento, se rediscutia o princípio que deveria reger a educação, devido ao "desenvolvimento da base industrial", isto é , colocava-se em discussão o princípio humanista próprio das escolas tradicionais e Gramsci (2004) admitia que o desenvolvimento industrial requeria uma escola profissional, "mas não manual”, fazendo- 
se necessário ao próprio desenvolvimento industrial da sociedade moderna que a escola formasse "um novo tipo de intelectual urbano", por conseguinte "a divisão fundamental da escola em clássica e profissional era racional" (GRAMSCI, 2004, p. 34).

A análise gramsciana admite a necessidade de se reformar o sistema educacional para formar os profissionais da indústria, por enxergar que o problema não se concentra na industrialização e sim na maneira adotada pelo governo para resolver essa problemática, bem como na vinculação ao objetivo de perpetuar a forma de sociabilidade dividida em classes antagônicas, cindida em trabalho manual e intelectual, o que se desdobra na escola através da divisão entre o ensino profissional-manual e o ensino intelectual. Nos termos de Gramsci (2004), a crítica à velha escola era justa porque, no limite, tratava-se de um modelo de escola que refletia, sobretudo, o tipo de sociedade então existente e que entrava em agonia. Aquele momento de grandes transformações no processo produtivo é colocado por ele como algo necessário ao desenvolvimento da sociedade.

Atentemos, contudo, para a forma como Gramsci (2004, p. 34) retrata o caráter das grandes indústrias em conexão com o sistema em que se inserem:

Pode-se observar, também, que os órgãos deliberativos tendem cada vez mais a diferenciar sua atividade em "dois aspectos "orgânicos": o deliberativo, que lhes é essencial, e o técnico-cultural, onde as questões sobre as quais é preciso tomar decisões são inicialmente examinadas por especialistas e analisadas cientificamente. Esta atividade já criou todo um corpo burocrático de nova estrutura, pois - além dos escritórios especializados de pessoas competentes, que preparam o material técnico para os corpos deliberativos cria-se um segundo corpo de funcionários, mais ou menos "voluntários" e desinteressados, escolhidos, a cada oportunidade, nas indústrias, nos bancos, nas finanças. Este é um dos mecanismos através dos quais a burocracia de carreira terminou por controlar os regimes democráticos, os parlamentos; atualmente, o mecanismo vai se ampliando organicamente e absorve em seu círculo os grandes especialistas da atividade prática privada, que controla assim os regimes e a burocracia (grifos nossos).

Manacorda (2008, p. 93) entende que “[...] o seu ponto de referência é, também neste aspecto, o industrialismo e a nova fase do processo histórico", o que nos leva a indicar que Gramsci deu tratamento a um fenômeno que surgia naquele momento e que é cada vez mais levado ao extremo na sociedade atual: a hierarquização dentro das fábricas e de outras instituições - divisão social do trabalho - que, segundo os grandes especialistas, chamados de deliberativos por Gramsci (2004), controlam as decisões dentro dos processos de produção apartados do corpo de técnicos que executam o trabalho. Gramsci (2004) aponta ser esse um dos motivos pelo qual se forma aquilo que denominou como burocracia de carreira, referindo-se àqueles profissionais que acabam por gozar de determinados privilégios dentro das empresas ou em instituições estatais e, por isso, sucumbem a defender os interesses dos patrões e se põem contra a classe trabalhadora, em nome de algumas benesses.

Devido ao processo de complexificação social, advindo do desenvolvimento industrial e denominado por Gramsci (2004) de "desenvolvimento orgânico necessário", surge a necessidade do desenvolvimento de organismos e instituições que possibilitem integrar o pessoal qualificado tecnicamente às atividades práticas administrativas com o pessoal especializado na política. Toda tentativa de barrar ou negar esse desenvolvimento, redundaria numa tentativa frustrada, pois, o "[...] antiamericanismo [antindustrialismo] é antes cômico que estúpido [...]" (GRAMSCI apud MANACORDA, 2008, p. 1). 
Assim, surge a necessidade de modificar o processo de formação dessa cisão que ocorre entre essas duas categorias distintas, que consiste em formar o técnico político, superando a sua falta de entendimento das questões que regem a administração do processo produtivo, e, por outro lado, formar funcionários especialistas que sejam capazes de deliberar, tomar decisões acerca de questões políticas. Nessa lógica, um dirigente político, por exemplo, que só esteja preparado para versar de forma abstrata sobre questões jurídicas, ou seja, afastado dos problemas reais que sofre a população, torna-se um perigo para a vida estatal, uma vez que ele não terá condições de criar ou, pelo menos, optar pela alternativa mais acertada acerca das soluções apontadas pelos especialistas.

Gramsci (2004, p. 33-34) assinala que essa crise do sistema escolar encontra uma solução na forma de uma Escola Unitária. Em suas palavras:

A crise terá uma solução que, racionalmente, deveria seguir esta linha: escola única inicial de cultura geral, humanista, formativa, que equilibre de modo justo o desenvolvimento da capacidade de trabalhar manualmente (tecnicamente, industrialmente) e o desenvolvimento das capacidades de trabalho intelectual. Deste tipo de escola única, através de repetidas experiências de orientação profissional, passar-se-á a uma das escolas especializadas ou ao trabalho produtivo.

Entendemos essa escola "única" como sinônimo de comum a todos, uma mesma escola para todos os indivíduos, uma vez que nesse momento o ensino profissional era destinado às classes subalternas e o ensino humanista, intelectual, era destinado às classes dominantes. E "única" também teria o sentido de promover um equilíbrio entre formar no estudante uma capacidade de trabalhar manualmente, assim como desenvolver o exercício do trabalho intelectual. Contudo, somente depois de adquirir uma série de conhecimentos, e, também, nas palavras do revolucionário sardo, "uma consciência moral e social sólida e homogênea" (GRAMSCI, 2004, p. 39), passar-se-ia a uma das escolas técnicas ou ao processo de trabalho. Gramsci defende o aprendizado autônomo e espontâneo do aluno somente numa fase em que este obteve uma 'base já atingida de 'coletivização' do tipo social", ou seja, somente depois de o aluno ter se apropriado de todo um legado de conhecimentos produzido pelo conjunto da humanidade ${ }^{10}$.

Gramsci (2004) sistematiza como deve ocorrer a organização da escola unitária e a quem compete garantir essa educação para toda a população, no caso, ao Estado. Em suas elaborações sobre a proposta de uma Escola Unitária, inicia abordando a questão do currículo, alertando que este precisa estar vinculado à função da escola de desenvolver o ensinamento de uma moral aos estudantes, entendendo moral como um conjunto de normas e valores que regem uma sociedade e que seriam imprescindíveis à convivência entre os seres humanos. Insiste, também, na necessidade desse modelo escolar assumir a função de permitir o ingresso dos indivíduos no processo de trabalho, sem, contudo, restringir-se a uma educação que forme exclusivamente para o mercado de trabalho capitalista, uma vez que fica muito claro em suas palavras o apelo à "escola unitária ou de formação humanista" (GRAMSCI, 2004, p. 36). Aponta, por fim, a necessidade de o Estado assumir as despesas educacionais, desresponsabilizando a família dessa tarefa.

Naquele momento histórico, abrir-se-ia a possibilidade de utilizar a educação como estratégia política do Estado operário, contribuindo para a superação da cisão entre trabalho manual e intelectual, pois, ao mesmo tempo em que seria organizado o processo produtivo, de acordo com o trabalho livre associado, a escola e as demais instituições estariam voltadas à formação de novos indivíduos capazes de viver nessa nova forma de 
sociabilidade, que começaria a ser implantada com a tomada do poder por parte dos comunistas. Sobre essa questão, vejamos as palavras de Nosella (1992, p. 115):

Sem dúvida, existe uma relação vital entre Escola Unitária e Sociedade Unitária. Não uma relação mecânica de causa e efeito; é uma relação do tipo orgânico cujo princípio vital e central, porém, não parte da escola e sim do Estado que coordena a sociedade ou do Partido.

A assertiva de Nosella (1992) converge com a posição do revolucionário sardo sobre a necessidade de superação da lógica do capital pois, para o secretário geral do Partido Comunista Italiano,

$\mathrm{O}$ advento da escola unitária significa o início de novas relações entre trabalho intelectual e trabalho industrial não apenas na escola, mas em toda a vida social. $O$ princípio unitário, por isso, irá se refletir em todos os organismos de cultura, transformando-os e emprestando-lhes um novo conteúdo. [...] Num novo contexto de relações entre a vida e cultura, entre trabalho intelectual e trabalho industrial as academias deveriam se tornar a organização cultural (de sistematização, expansão e criação intelectual) daqueles elementos que, após a escola unitária, passarão para o trabalho profissional, bem como um terreno de encontro entre estes e os universitários" (NOSELLA, 1992, p. 40, grifos nossos).

Nessa passagem, fica evidente a perspectiva revolucionária assumida por Gramsci na elaboração da Escola Unitária ao retratar como deveria se reorganizar o sistema educacional num momento em que se abrisse uma situação revolucionária e começassem a se estabelecer novas relações entre trabalho manual e intelectual. Entendemos essas novas relações como o início da superação da alienação do trabalho. Não temos condições de explorar aqui essa categoria marxiana, mas podemos dizer, em breves palavras, que esse seria um momento propício para que os trabalhadores pudessem organizar livremente a produção dos meios de subsistência de acordo com as necessidades vinculadas ao bemestar social, e não ao mercado, com voz ativa nas decisões e soluções dos problemas sociais deliberadas pelos dirigentes políticos de um Estado de transição comandado pela classe trabalhadora.

Gramsci (2004, p. 37) detalha aspectos metodológicos sobre como deveria organizar-se essa Escola Unitária. A esse respeito, vale retomar uma citação frequentemente utilizada por diversos autores, de forma descolada, a nosso juízo, do contexto de sua obra, o que permite, erroneamente, imaginar um Gramsci simplesmente didaticista, a ditar regras e receitas pedagógicas. Senão, vejamos:

A escola unitária deveria corresponder ao período representado hoje pelas escolas primárias e médias, reorganizadas não somente no que diz respeito ao método de ensino, mas também no que toca à disposição dos vários graus da carreira escolar. O nível inicial da escola elementar não deveria ultrapassar três-quatro anos e, ao lado do ensino das primeiras noções "instrumentais" da instrução (ler, escrever, fazer contas, geografia, história), deveria desenvolver sobretudo a parte relativa aos "direitos e deveres", atualmente negligenciada, isto é, as primeiras noções do Estado e da sociedade, enquanto elementos primordiais de uma nova concepção do mundo que entra em luta contra as concepções determinadas pelos diversos ambientes sociais tradicionais, ou seja, contra as concepções que poderíamos chamar de folclóricas. O problema 
didático a resolver é o de abrandar e fecundar a orientação dogmática que não pode existir nestes primeiros anos. $O$ resto do curso não deveria durar mais de seis anos, de modo que aos quinze ou dezesseis anos, já deveriam estar concluídos todos os graus da escola unitária (grifos nossos).

No trecho acima, Gramsci (2004) esclarece questões metodológicas fundamentais que se desdobram dos princípios e da finalidade que se quer atingir. Acreditamos que essa passagem pode possibilitar um desvirtuamento do pensamento de Gramsci como teórico da educação. Sendo assim, torna-se fundamental apanhar a essência pontuada por nosso autor acerca dessas questões específicas do complexo educacional, sem perder de vista o contexto histórico em que Gramsci vislumbrava a efetivação desse modelo educacional.

$\mathrm{Na}$ verdade, Gramsci (2004, p.36) nos chama a atenção para o fato de que a resolução do problema da crise que se abatia sobre a educação demandaria "[...] uma enorme ampliação da organização prática da escola, isto é, dos prédios, do material científico, do corpo docente, etc.". Isto possibilita o entendimento de que a construção de prédios, a compra de materiais pedagógicos, a ampliação do corpo docente no âmbito da escola pública, vão de encontro aos interesses do sistema do capital que visa lucrar com a mercantilização ${ }^{11}$ da educação, como ocorre de forma aguda, a propósito, no momento de crise atual, em que o capitalismo necessita cada vez mais de mercados e o Estado reduz os gastos com o custeio da atividade social, escoando as verbas endereçadas à educação pública, frequentemente desviadas para a esfera privada, inclusive corroborando com o projeto de privatização com incentivos fiscais às empresas, dentre outras estratégias.

É importante observar que, deslocados os problemas educacionais da forma de sociabilidade em que estavam inseridos, poder-se-ia gerar a falsa impressão de que o problema central residia na falta de habilidade dos educadores para resolver as questões educacionais, fosse por falta de competência ou conhecimento. Essa visão exibe limites por tomar a educação apenas do ponto de vista gnosiológico, apanhando a escola, ademais, predominantemente, a partir de seus aspectos mais aparentes e imediatos. Apenas a partir da contextualização criteriosa, pode-se enxergar que a solução dos problemas educacionais demanda "um amplo projeto político coordenado pelo Estado [...]; não se trata de uma reforma educacional abstrata" (NOSELLA, 1992 p. 115), sendo, por isso, impossível a sua realização por um Estado que surge e se mantém - até hoje - para garantir o direito à propriedade privada, conforme assinalam Marx e Engels (2002, p. 27) no Manifesto Comunista: "o Estado é o balcão de negócios da burguesia".

Como discipliná-las [as massas trabalhadoras] e dar-lhes uma forma política que possua em si a virtude de se desenvolver normalmente, de se integrar continuamente, até se tornarem a estrutura (esqueleto) do Estado socialista no qual se encarnará a ditadura do proletariado? Como soldar o presente ao futuro, satisfazendo as urgentes necessidades do presente e trabalhando eficazmente para criar e 'antecipar' o futuro? [...] O Estado socialista já existe potencialmente nas instituições de vida social características da classe trabalhadora explorada. Articular entre si estas instituições, coordená-las e subordiná-las segundo uma hierarquia de competências e de poderes, centralizá-las fortemente significativa criar desde já uma verdadeira democracia operária, em eficiente e ativa contraposição ao Estado burguês em todas as suas funções essenciais de gestão [...] (GRAMSCI, 2004, p. 245).

Retomando as questões específicas do complexo educacional, Gramsci (2004, p. 38) atenta para algumas particularidades importantes, como veremos abaixo: 
[...] os alunos urbanos, pelo simples fato de viverem na cidade, já absorveram - antes dos seis anos - muitas noções e aptidões que tornam mais fácil, mais proveitosa e mais rápida a carreira escolar. $\mathrm{Na}$ organização interna da escola unitária, devem ser criadas, pelo menos, as mais importantes destas condições, além do fato, que se deve dar por suposto, de que se desenvolverá - paralelamente à escola unitária - uma rede de creches e outras instituições nas quais, mesmo antes da idade escolar, as crianças se habituem a uma certa disciplina coletiva e adquiram noções e aptidões pré-escolares. De fato, a escola unitária deveria ser organizada como escola em tempo integral, com vida coletiva diurna e noturna, liberta das atuais formas de disciplina hipócrita e mecânica, e o estudo deveria ser feito coletivamente, com a assistência dos professores e dos melhores alunos, mesmo nas horas do estudo dito individual, etc. (grifos nossos).

Algumas dessas questões específicas do complexo educacional elencadas por Gramsci (2004), tais como, ensino em creches e a organização de escolas de tempo integral, ainda que em circunstâncias diferentes, já estão colocadas em prática na atual rede de ensino, e não só na rede pública de ensino, mas, principalmente, na rede privada, fato que reforça nossa defesa já mencionada de que o problema central da educação não é a falta de conhecimento técnico para solucionar os problemas educacionais. Com efeito, essa solução esbarra nos interesses privados; implica em perdas financeiras por parte dos grandes capitalistas da educação; exige que o Estado rompa com as grandes empresas e deixe de financiar os banqueiros, para investir adequadamente em educação, embora esta atitude, por si só, não possa operar uma transformação estrutural em uma ordem capitalista.

Conforme já apontado por Ribeiro (2015), a profissionalização precoce dos alunostrabalhadores constitui um grande obstáculo para o desenvolvimento livre da ciência e das forças produtivas, além de contribuir para o subjugo da educação aos imperativos do mercado e das agências multilaterais. Ao complexo educativo é imposta a chantagem da qualificação profissional como uma promessa de ascensão social e garantia de empregabilidade. Este debate representa o entrave de várias correntes de pensamento e, em última análise, evidencia as determinações da postura do Estado brasileiro quanto ao reforço do dualismo educacional.

Tornou-se confortável para o Estado, ainda de acordo com Ribeiro (2015), que a propaganda oficial apresente dados sobre o aumento do acesso das classes populares aos cursos profissionalizantes, o que alimenta a falsa impressão de grandes oportunidades dadas aos jovens que, na verdade, encobrem a precariedade massificada por trás do falacioso acesso a uma suposta era tecnológica. Registramos o quadro de profissionalização aligeirada, os dispositivos legais que embasam o discurso da qualificação profissional e a fragilidade dos governos frente às demandas da formação de mão de obra, bem como a submissão do Estado às pressões das agências multilaterais.

Outra questão relativa à proposta educacional da Escola Unitária que merece a devida atenção é a defesa de uma escola criadora, fundada na disciplina, na conquista da autonomia e na elevação de todos os alunos a um mesmo nível de cultura. Contudo, a escola criadora requer vontade e interesse espontâneos pelo conhecimento e coloca o professor apenas como um mero orientador. Nesse sentido, enfatiza Gramsci (2004, p. 3940) que:

A escola criadora é o coroamento da escola ativa: na primeira fase, tendese a disciplinar e, portanto, também a nivelar, a obter uma certa espécie 
de "conformismo" que pode ser chamado de "dinâmico"; na fase criadora, sobre a base já atingida de "coletivização" do tipo social, tende-se a expandir a personalidade, tornada autônoma e responsável, mas com uma consciência moral e social sólida e homogênea. Assim, escola criadora não significa escola de "inventores e descobridores"; indica-se uma fase e um método de investigação e de conhecimento, e não um "programa" predeterminado que obrigue à inovação e à originalidade a todo custo. Indica que a aprendizagem ocorre sobretudo graças a um esforço espontâneo e autônomo do discente, e no qual o professor exerce apenas uma função de guia amigável, como ocorre ou deveria ocorrer na universidade (grifos nossos).

Sobral (2010) pontua algumas apropriações indevidas como, por exemplo, no caso do construtivismo vigente. Este modelo educacional atribui, no âmbito da educação infantil, valor absoluto à espontaneidade da criança, além de alocar o professor apenas como um facilitador do processo. Essa concepção, apesar de parecer semelhante, contraria frontalmente a proposta de Gramsci, que vislumbra o exercício da autonomia no momento em que o estudante alcançasse maturidade intelectual e formação moral e cultural sólida.

Após tecer uma série de considerações sobre o sistema educacional - antes e depois da reforma Gentile - e de como deveria ser uma Escola Unitária a partir da união entre desenvolvimento manual e intelectual, Gramsci (2004) começa a traçar observações em torno do princípio educativo. A função da escola, no entender do autor, é preparar os novos indivíduos para a vida em sociedade, ensinando-lhes como se dá a organização da vida social, em que o homem transforma a natureza. Dessa forma, o que determina o processo de aprendizagem é o trabalho entendido como "atividade teórico-prática". Gramsci (2004, p. 43) afirma que

[...] o princípio educativo no qual se baseavam as escolas primárias era o conceito de trabalho, que não pode se realizar em todo seu poder de expansão e de produtividade sem um conhecimento exato e realista das leis naturais e sem uma ordem legal que regule organicamente a vida dos homens entre si, ordem que deve ser respeitada por convicção espontânea e não apenas por imposição externa, por necessidade reconhecida e proposta a si mesmo como liberdade e não por simples coerção. $O$ conceito e o fato do trabalho (da atividade teórico-prática) é o princípio educativo imanente à escola primária, já que a ordem social e estatal (direitos e deveres) é introduzida e identificada na ordem natural pelo trabalho (grifos nossos).

É interessante observar nessa passagem a definição de trabalho, que se coaduna com aquela explicitada nos clássicos do marxismo, a exemplo de Lukács, a partir da qual o trabalho é concebido como a mediação entre o homem e a natureza. Ainda nessa citação, Gramsci (2004) prolonga suas considerações sobre a escola existente e constata que as escolas primárias destinadas à classe trabalhadora, antes da reforma Gentile, se organizavam mediante o trabalho, ou seja, se destinavam a ensinar aos alunos noções concretas sobre as leis naturais e sociais, entendendo o trabalho como o "princípio educativo imanente à [essa] escola primária". Gramsci (2004) tem nas relações sociais de produção, no trabalho, o elemento determinante de qualquer forma de sociabilidade, portanto, é essa a categoria fundante do mundo dos homens. Em comum acordo com Lukács (2012), o revolucionário italiano se refere a essa categoria como imanente à 
organização e ao programa escolar, "[...] já que a ordem social e estatal (direitos e deveres) é introduzida e identificada na ordem natural pelo trabalho".

Esse autor, como visto acima , ao afirmar que o trabalho não pode se realizar "em todo seu poder de expansão e de produtividade sem um conhecimento exato e realista das leis naturais", coaduna, por um lado, com os limites impostos à escola italiana na sua oferta de educação para os trabalhadores, uma vez que o princípio educativo do trabalho é importante, mas está delimitado pela ordem social e política na qual a escola se insere; por outro lado, incorpora a necessidade de se conhecer os nexos causais (relação de causa e efeito), para que, a partir desse conhecimento, os novos indivíduos aprendam a viver em sociedade. Entendemos que nessa passagem evidencia-se o complexo da educação como um complexo indispensável à reprodução do ser social.

Foi possível verificar que Gramsci (2004) elabora tal tese no sentido de justificar que a organização do trabalho escolar e os princípios filosóficos que regem a educação encontram suas raízes no trabalho, que, por sua vez, guarda com o complexo educativo uma relação de autonomia relativa e reciprocidade dialética. Partindo do pressuposto de Marx e Engels (1996) de que são as condições materiais de existência que determinam a vida do homem, ele entende que é no mundo da produção (nas novas relações de produção), que a escola se organizaria. $\mathrm{O}$ fato de afirmar que "o trabalho é o princípio imanente" pode ser compreendido a partir de Lukács (2012), tomando a educação, por excelência, como um complexo da reprodução social. Portanto, a escola se organizaria de acordo com as relações de produção.

Dessa maneira, explica Gramsci (2004, p. 43) o seguinte:

O conceito do equilíbrio entre ordem social e ordem natural com base no trabalho, na atividade teórico-prática do homem, cria os primeiros elementos de uma intuição do mundo liberto de toda magia ou bruxaria, e fornece o ponto de partida para o posterior desenvolvimento de uma concepção histórica, dialética, do mundo, para a compreensão do movimento e do devir, para a avaliação da soma de esforços e de sacrifícios que o presente custou ao passado e que o futuro custa ao presente, para a concepção da atualidade como síntese do passado, de todas as gerações passadas, que se projeta no futuro. É este o fundamento da escola primária; que ele tenha dado todos os seus frutos, que no corpo de professores tenha existido a consciência de seu dever e do conteúdo filosófico deste dever, é um outro problema, ligado à crítica do grau de consciência civil de toda a nação, da qual o corpo docente era apenas uma expressão, ainda que amesquinhada, e não certamente uma vanguarda (grifos nossos).

O revolucionário italiano enxergava a necessidade de unir o que foi separado na história pela luta de classes. Para que uma classe pudesse ter o controle da ordem social sobre a outra, foi necessário separar trabalho manual e intelectual, ou seja, o controle da produção e os meios de produção, de forma que aqueles que produzem a riqueza social perdessem o conhecimento total do processo de produção. Aqui, encontramos uma ratificação do conceito de trabalho como atividade teórico-prática do homem, que deve servir de base para equilibrar a ordem social e a natural, sendo, esse equilíbrio, o ponto de partida para o posterior desenvolvimento de uma concepção histórica que se inicia num Estado de transição em que o trabalho é o princípio educativo da Escola Unitária, com o objetivo de preparar os novos indivíduos para a concretização de uma liberdade universal.

Daremos tratamento, nesse momento, à interpretação de $\operatorname{Nosella~}^{12}(1992$, p. 114) acerca da elaboração gramsciana de Escola Unitária: 
[...] Gramsci primeiramente estabelece uma idade (16-18) anos como divisor de águas. Até aquela idade estabelece universalmente uma escola unitária que resgate o princípio educativo da "cultura desinteressada" própria da escola humanista tradicional, e o integre com o princípio educativo próprio das escolas profissionais, isto é, com o trabalho técnico-profissional. Somente depois dos $16 \backslash 18$ anos (após o $2^{\circ}$ grau) o princípio da cultura formativa desinteressada perde a primazia (sem desaparecer) em favor dos princípios da cultura imediatamente produtiva ou especializada (interessada). [...] Nesse sentido o trabalho se torna princípio educativo universal, tanto na fase da formação desinteressada (escola unitária) quanto na da formação especializada (grifos nossos).

É importante ressaltar que Nosella (1992, p. 114) chega às suas conclusões, a partir das elaborações de Gramsci sobre o princípio humanista próprio da escola tradicional e o princípio do trabalho próprio das escolas profissionais, análise concluída com a máxima de que "o trabalho se torna princípio educativo universal". O que significa dizer que o trabalho como princípio educativo da Escola Unitária aparece de maneira mediada por ser nessa fase entre os 16 e 18 anos que devem ser ensinadas as leis naturais e as leis sociais que organizam a vida na natureza e em sociedade.

Depois de teorizar sobre o princípio educativo, Gramsci (2004, p. 43-4) introduz uma discussão acerca da necessária relação entre instrução e educação, negada pela pedagogia idealista. $\mathrm{O}$ autor ressalta, com toda precisão, tal imbricação na citação que se segue:

Não é completamente exato que a instrução não seja também educação: a insistência exagerada nessa distinção foi um grave erro da pedagogia idealista, cujos efeitos já se vêem na escola organizada por esta pedagogia. Para que a instrução não fosse igualmente educativa, seria preciso que o discente fosse uma mera passividade, um "recipiente mecânico" de noções abstratas, o que é absurdo, além de ser "abstratamente" negado pelos defensores da pura educatividade precisamente contra a mera instrução mecanicista (...). Por isso, pode-se dizer que, na escola, o nexo instrução-educação somente pode ser representado pelo trabalho vivo do professor, na medida em que o professor é consciente dos contrastes entre o tipo de sociedade e de cultura que ele representa e o tipo de sociedade e cultura representado pelos alunos; e é também consciente de sua tarefa, que consiste em acelerar e disciplinar a formação da criança conforme o tipo superior em luta com o tipo inferior. Se o corpo docente é deficiente e o nexo instrução-educação é abandonado, visando a resolver a questão do ensino de acordo com esquemas abstratos nos quais se exalta a educatividade, a obra do professor se tornará ainda mais deficiente: ter-se-á uma escola retórica, sem seriedade, pois faltará a corporosidade material do certo e o verdadeiro será verdadeiro só verbalmente, ou seja, de modo retórico (grifos nossos).

Percebe-se, portanto, em referência à relação educação e instrução, que esse par não forma dois elementos completamente distintos; como queriam os "defensores da pura educatividade", seria necessário que o estudante fosse um ser absolutamente passivo, inerte. Gramsci (2004) defende a existência de um nexo entre educação e instrução. O professor, mediante a constatação da diferença entre a forma de sociabilidade, a nova 
cultura que ele representa e a sociedade e a cultura vivenciadas e representadas pelos alunos, precisaria ter a consciência de que sua tarefa era formar os trabalhadores de acordo com esse novo modelo societário e cultural, que seria um padrão superior do grau de desenvolvimento da humanidade. Destarte, ele chama a atenção para o fato de que o professor, ao não fazer a devida relação entre educação e instrução, abandonando a segunda em primazia da primeira, torna sua ação mais abstrata, afastando a corporeidade aos ensinamentos e às palavras, fazendo da escola um lugar de mera retórica. O ensino teria de partir da realidade concreta, e essa, por sua vez, comporta a sociedade com todas as suas teias de relações e tem como base as relações sociais de produção.

A linha de raciocínio de Gramsci (2004), após analisar a crise escolar italiana, detém-se no papel do professor num momento de reestruturação do sistema educacional. Essa análise, vale ressaltar, partia de um pensador marxista o que, necessariamente, toma o objeto em foco - a educação - a partir da maior quantidade de elementos determinantes possíveis para compreender o que ocorre naquele momento de crise social e educacional. Apontou, como elemento determinante para a crise enfrentada pela escola, o currículo, temática que procurou relacionar com o papel do professor, dentre outros fatores.

Por fim, o marxista sardo chama atenção para a função social da escola na sociedade de classes. Sobre este aspecto, enfatiza que a escola tradicional poderia ser classificada como oligárquica, pois cumpria a função de perpetuar a estratificação social, isto é, a divisão da sociedade em classes. Por outro lado, pondera que, ao mesmo tempo, não poderia ser oligárquica pelo seu modo de ensino, qual seja, formar dirigentes, pois esse deveria ser o verdadeiro sentido da escola, formar sujeitos capazes "[...] de pensar, de estudar, de dirigir ou de controlar quem dirige" (GRAMSCI, 2004, p. 49). Pois, "Não é a aquisição de capacidades de direção, não é a tendência a formar homens superiores que dá a marca social de um tipo de escola" (Ibidem, p. 49).

A Escola Unitária constitui uma alternativa de reorganização do sistema educacional para um momento de transição do capitalismo para o comunismo, sendo a expressão mais fiel do princípio educativo elencado por Gramsci (2006) - o trabalho - que, acreditava ele, estar em comum acordo com os pressupostos marxianos, "[...] é a forma própria através da qual o homem participa ativamente na vida da natureza, visando a transformá-la e socializá-la cada vez mais profunda e extensamente" (GRAMSCI, 2004, p. 43). Logo, a tese do trabalho como princípio educativo precisa ser analisada a partir de um ponto de vista de classe, uma vez que se encontra vinculada na obra de Gramsci à resolução dos dilemas do proletariado - formar indivíduos com capacidade técnica e política, para exercerem a função de dirigentes do processo produtivo visando a transformação da sociedade.

Apontamos que a vinculação entre trabalho produtivo e educação é um dos elos para que possamos pensar o início da superação da cisão entre trabalho manual e intelectual. Para o autor italiano, a categoria que melhor explicita esse pensamento é a tese do trabalho como princípio educativo, que só pode ser radicalizada num momento de transição do capitalismo para o comunismo pois, apenas formando novos homens, com amplas capacidades (de direção técnica e política, repetimos) que se criarão as condições para se reorganizar a produção, em que todos sejam técnicos e todos tenham a capacidade de administrar o controle ar da produção, da distribuição e do consumo dos bens materiais, naturais e espirituais produzidos pelo trabalho humano. 


\section{Considerações finais}

O estudo acerca das possibilidades e dos limites de efetivação de uma educação que tenha como horizonte a emancipação humana, no seio de uma sociedade pautada na exploração do homem pelo homem, desdobra-se numa contradição assim explicitada por Marx e Engels (1992, p. 96): se "[...] por um lado, é necessário modificar as condições sociais para criar um novo sistema de ensino; por outro, falta um sistema de ensino novo para poder modificar as condições sociais [...]". Apesar de encontrarmos em Marx e Engels (1992) as bases teórico-filosóficas de uma concepção de educação perspectivada pelo desenvolvimento pleno - omnilateral, das capacidades humanas -, Gramsci (2004) no seu tempo, tentou sistematizar uma proposta político-educacional fundamentada nos pressupostos marxianos, nos termos da educação unitária, que tem como base o trabalho como princípio educativo.

A teoria da Escola Unitária teria sido desenvolvida por Gramsci no seu famoso Caderno 12, porém já nos Escritos Políticos o autor reconhecia a necessidade de elaboração de uma proposta educacional que articulasse a teoria e a prática, na sua estreita relação com a construção de uma nova forma de sociabilidade, pautada no trabalho livremente associado.

A forma como a obra de Gramsci entrou no Brasil, pelas mãos da Editora Civilização Brasileira, como uma tradução da edição temática elaborada por Togliatti e publicada pela Editora italiana Einaudi, possibilitou uma série de apropriações indébitas de suas elaborações, nos mais diversos aspectos. Apesar disso, não podemos deixar de reconhecer o esforço dos intelectuais envolvidos no projeto de divulgação das ideias gramscianas na Itália e no Brasil. Dentre essas apropriações indevidas, estão aquelas que instigaram nosso esforço de pesquisa, a saber: a tentativa de minimização da dimensão revolucionária do pensamento de Gramsci, o que se traduz a partir da desconsideração dos escritos que marcam sua militância comunista, isto é, da unidade orgânica entre os escritos pré-carcerários e seus cadernos escritos no cárcere; a utilização aleatória dos seus conceitos, desvinculando-os de sua relação com a totalidade de sua obra; a redução da concepção gramsciana de educação à organização escolar; o afastamento da tese do trabalho como princípio educativo - categoria chave da proposta político-educacional de Gramsci, por parte de alguns educadores do campo teórico-prático do marxismo.

Gramsci (2004) ao afirmar o trabalho como princípio imanente à escola primária ajuda-nos a compreender que a realização do trabalho (mediação homem-naturezasociedade) não pode prescindir do conhecimento das leis naturais e "[...] sem uma ordem legal que regule organicamente a vida dos homens entre si" (GRAMSCI, 2004, p. 43), ou seja, é o trabalho quem determina, em última instância, por uma série de complexas mediações, os conteúdos que precisam ser aprendidos mediante o ato educativo.

Conforme afirma Saviani (2007, p. 154), com base em Marx “[...] [o homem] não nasce sabendo produzir-se como homem. Ele necessita aprender a ser homem, precisa aprender a produzir sua própria existência”. O processo educativo seria responsável, portanto, pela apropriação do já existente (leis naturais e sociais) para, a partir daí, recriar novas e elevadas formas de garantir a existência do ser humano. Aqui, a reprodução do existente e a produção do novo, mediante a educação, guardam relações diretas e indiretas com o processo de trabalho.

Compreendemos que a elaboração de Gramsci em torno da educação no conjunto de sua obra ultrapassa, em primeiro lugar, as fronteiras da educação institucional e assume um caráter extremamente político de educação dos trabalhadores, a fim de contribuir para a formação de uma consciência de classe, estando, portanto, atrelada ao momento histórico 
vivenciado pelo militante sardo. Dessa forma, Gramsci pensava como educar a classe trabalhadora diante do que era possível realizar de acordo com uma determinada conjuntura.

Constatamos com a análise, a partir da leitura imanente do Caderno 12, a vinculação da proposta político-pedagógica de Gramsci com o projeto de construção de uma nova forma de sociabilidade. Compreendemos que Gramsci (2004) não tinha a ilusão de forjar na forma de sociabilidade capitalista, em que o Estado burguês organiza a educação institucionalizada pela escola, um sistema educacional voltado para a formação de um novo homem, nem de criar uma escola paralela, como uma espécie de criação de uma ilha socialista.

Identificamos que a tese do trabalho como princípio educativo está contida nos escritos pré-carcerários de maneira transversal. Buscamos pontuar que Gramsci (2004) ao expor nos escritos políticos a preocupação de educar o proletariado para a liberdade, já estaria manifestando a necessidade da formação técnica e política dos trabalhadores necessária tanto para a realização das suas necessidades materiais quanto para a conquista da sua liberdade, tornando-os, assim, técnicos-políticos-dirigentes, ou seja, condição sine qua non para a realização da sua tarefa histórica, a construção do socialismo.

O estudo aponta que a elaboração de Gramsci (2004) em torno da categoria do trabalho como princípio educativo resguarda o trabalho como fundamento da sociabilidade humana, tendo como ponto de partida a apropriação de todos os avanços, ao nível da ciência, da técnica e da organização, advindos com a revolução industrial.

Com base na pesquisa desenvolvida, é possível afirmar, em primeiro lugar, o que a tese do trabalho como princípio educativo não significa: 1) afirmar o trabalho alienado, abstrato, próprio da sociabilidade capitalista, como princípio educativo; 2) formar a criança e o jovem para o mercado de trabalho capitalista ou, simplesmente, inseri-los na fábrica; 3 ) afirmar a identidade entre trabalho e educação.

No caso específico da transição do capitalismo ao socialismo, após a tomada do poder pela classe trabalhadora, a escola, na perspectiva gramsciana, nos termos da proposta da Educação Unitária, cumpriria um papel decisivo na formação e consolidação de uma nova cultura, entendida como a formação de um novo homem, ou seja, na acepção de Gramsci (2004, p. 58), “[...] disciplina do próprio eu interior”.

Em suma, a proposta de Gramsci (2004) acerca da educação unitária - na base da qual se encontra a tese do trabalho como princípio educativo -, fora elaborada não para o momento histórico atual - sociabilidade capitalista em crise profunda - mas para um contexto de transição do capitalismo ao comunismo, após a revolução socialista e a implantação do Estado operário de transição.

Finalizamos cientes do inacabamento desta pesquisa, com a certeza de que, nos limites do tempo, não nos fora possível esgotar esse debate em torno da tese do trabalho como princípio educativo. Estudar Gramsci significa compreendê-lo no momento histórico em que viveu. Trazer suas reflexões para a realidade atual necessitaria, portanto, de uma série de mediações, dentre as quais, a análise acurada da conjuntura do momento histórico atual e, decorrentemente, daquilo que é possível realizar no atual momento histórico. 


\section{Referências}

COSTA, Frederico J. F. Ideologia e educação na perspectiva da ontologia marxiana. 2007. Tese (Doutorado em Educação). Universidade Federal do Ceará. Faculdade de Educação. Fortaleza, 2007.

DEL ROIO, M. Gramsci e o fascismo. Tema, São Paulo, p. 06-17, 2002.

DEL ROIO, Marcos. Gramsci e a educação do educador. Caderno Cedes, Campinas, SP, v. 26, n. 70, set./dez. 2006.

GRAMSCI, Antônio. Caderno 12. IN: Cadernos do Cárcere. Vol. 2 (Os intelectuais. O princípio educativo. Jornalismo). Edição e Tradução de Carlos Nelson Coutinho. Coedição de Luiz Sérgio Henriques e Marco Aurélio Nogueira. $4^{\mathrm{a}}$ Ed. - Rio de Janeiro: Civilização Brasileira, 2004.

JIMENEZ, Susana V.; MENDES SEGUNDO, Maria das Dores. Erradicar a pobreza e reproduzir o capital: notas críticas sobre as diretrizes para a educação no novo milênio. Cadernos de Educação. Pelotas, Editora da UFPEL, Ano 16, N. 28, Jan-Jun 2007, pp. 119 -138 .

LEHER, Roberto. Da ideologia do desenvolvimento à ideologia da globalização: a educação como estratégia do Banco Mundial para "alívio" da pobreza. 1998. Tese (Doutorado em Educação). Faculdade de Educação da Universidade de São Paulo. (FEUSP). São Paulo, 1998.

LUKÁCS, Gÿorg. Para uma ontologia do ser social I. São Paulo: Boitempo, 2012.

MANACORDA, Mario Alighiero. O princípio educativo em Gramsci: Americanismo e conformismo. Tradução: William Laços, Ed. Alínea, campinas - SP, 2008. (Coleção educação em debate).

MARX, Karl. Manuscritos econômico-filosóficos. Tradução de Artur Morão. Lisboa, Portugal: Edições 70, 1993.

MARX, Karl; ENGELS, Friedrich. A ideologia alemã. Tradução de José Carlos Bruni e Marcos Aurélio Nogueira. 10 ed. São Paulo: Ed. Hucitec, 1996.

MARX, Karl; ENGELS, Friedrich. Textos sobre educação e ensino. $2^{\mathrm{a}}$ Ed. Lisboa: Moraes Editora, 1992.

MIRANDA, Victor Garciac; AZEVEDO, Mário Luiz Neves de. Reforma Gentílica: por uma educação de espírito. I Encontro de Pesquisa em Educação, IV Jornada de Prática de Ensino, XIII Semana de Pedagogia da UEM: "Infância e Práticas Educativas" Arq Mudi. 2007; 11(Supl.2):50-4, 2007.

NOSELLA, Paolo. A escola de Gramsci. 3ª Ed rev. e atual. São Paulo. Ed. Cortez, 1992.

NOSELLA, Paolo. Ensino médio: em busca do princípio pedagógico. Educ. Soc. . Campinas: CEDES, v. 32, n. 117, p. 1.051-1.066, out./dez. 2011. Disponível em: http:// 
www.cedes.unicamp.br. Acesso em: 11/09/2011.

RIBEIRO, Ellen C.S. Ensino médio integrado no Estado do Ceará: a escola do trabalhador sob a lógica empresarial. Dissertação (Mestrado em Educação). Universidade Estadual do Ceará (UECE). Fortaleza, 2015.

SAVIANI, Dermeval. Escola e democracia. $35^{\text {a }}$ Ed. Autores associados. Campinas, SP. (Coleção Polêmicas do nosso tempo: vol. 5), 2002.

SAVIANI, Dermeval. Trabalho e educação: fundamentos ontológicos e históricos. Revista Brasileira de educação. Rio de Janeiro: ANPED; Campinas: Autores Associados. v. 12, n. 34, jan./abril 2007.

SOBRAL, Karine Martins. O trabalho como princípio educativo em Gramsci: ensaios de compreensão à luz da ontologia marxiana. Dissertação (Mestrado em Educação). Universidade Estadual do Ceará (UECE). Fortaleza, 2010.

TONET, Ivo. Educação, cidadania e emancipação humana. Rio Grande do Sul; Ed. Unijuí, 2005. (Coleção fronteiras da educação).

1 Doutoranda em Educação pela Universidade Estadual do Ceará (UECE). Professora da Universidade Federal do Maranhão (UFMA). E-mail: karineufma2013@gmail.com

2 Mestra em Educaçãopela Universidade Estadual do Ceará (UECE). Professora da Rede Municipal de Fortaleza. E-mail: ellencristineribeiro@hotmail.com

${ }^{3}$ Doutor em Educação pela Universidade Federal do Ceará (UFC). Professor Adjunto da Faculdade de Educação, Ciências e Letras do Sertão Central (FECLESC-UECE). E-mail: deribaldo.santos@uece.br

${ }^{4}$ Doutora em Educação pela Universidade Federal do Ceará (UFC). Professora Adjunta da Universidade Estadual do Ceará (UECE).E-mail: Raquel.dias69@gmail.com

${ }^{5}$ Para uma análise mais aprofundada do fascismo, conferir Del Roio (2002).

${ }^{6}$ Há um estudo bastante interessante que apanha a ideologia em seu caráter ontológico, versando, ademais, sobre a imbricação entre educação e ideologia. Nesse sentido, conferir COSTA (2007).

${ }^{7}$ Sobre os limites da democracia e da cidadania, verificar Tonet (2005).

${ }^{8}$ É oportuno destacar que essa cisão se encontra hoje bem mais agudizada, desde que a educação passou a ser comandada pelos órgãos mundiais (Banco Mundial e FMI), que defendem declaradamente, em seus documentos oficiais, a universalização apenas da educação básica. Sobre a crítica marxista a diversos documentos, elaborados em conferências mundiais, conferir Jimenez e Mendes Segundo (2007), bem como Leher (1998).

9 Saviani (2002), um dos maiores responsáveis por trazer Gramsci para o debate educacional no Brasil, oferece uma elaboração bastante profícua sobre o legado gramsciano, em que o filósofo brasileiro utiliza as contribuições de Gramsci para analisar as teorias da educação no Brasil.

10 Sobre a função da educação de "transmitir o legado histórico aos novos indivíduos", conferir Saviani (2003) e Tonet (2005). Não temos condições de aqui apontarmos nem, em grandes linhas, as distinções existentes entre estes dois pesquisadores. Basta, para as pretensões deste artigo, indicarmos, muito 
sinteticamente, que Saviani, em linhas gerais, segue as indicações gramscianas sobre a natureza da educação, ou seja, trafegar para as gerações futuras o acumulado histórico da humanidade, o que é apropriado por Manacorda, Gaudêncio Frigotto, Newton Duarte, entre outros autores. Já, Tonet, embora se utilize de Saviani em algumas ocasiões, recorre a tese lukacsiana, pela qual a educação deve se empenhar em garantir ao sujeito os elementos para que ele possa conviver com o novo, com as novidades, com as possibilidades. Em uma expressão: para que ele possa escolher entre alternativas postas. Dessa posição, de modo geral, partilham, cada uma a seu termo, Sergio Lessa, Ademir Lazarine, entre outros teóricos.

${ }^{11}$ Sobre a mercantilização do ensino, conferir Jimenez e Rocha (2007).

12 Paolo Nosella, como nos expõe Del Roio (2008), saiu de uma posição teórica alinhada com os pressupostos do socialismo para se aproximar de posicionamentos liberais com fortes influências do pensador italiano Norberto Bobbio. Em comunicação apresentada no Seminário Nacional de Políticas para o Ensino Médio, evento patrocinado pelo Ministério da Educação, realizado em setembro de 2009 na cidade de Brasília, Nosella (2011, p. 1.062) defendeu a "luta política que visa tornar a sociedade mais justa e igualitária [...]". Embora essas ressalvas mereçam atenção e melhores investigações, entendemos que as interpretações de Nosella sobre a Escola Unitária sejam bastante pertinentes, motivos pelos quais as abordamos na presente comunicação.

Recebido: Março/2016.

Aprovado: Abril/2017. 